\title{
Research on optical 32QAM-OFDM-PON access scheme with different numbers of sub-carriers using DMT modulation
}

\author{
Yufeng Shao* (D), Ying Long, Anrong Wang, Zefu Tan, Guoping Lei, Zhengquan Hu, Yu Liu, Qinzheng Hu, \\ Zhuang Wang and Jie Yang
}

\begin{abstract}
An optical 32QAM-OFDM-PON system with different numbers of sub-carriers using discrete multitone (DMT) modulation and demodulation is designed and demonstrated by experiment. Electron-optic generation, directly photoelectric detection, and electrical self-mixing reception of 32QAM-OFDM downstream signals are achieved. $5 \mathrm{~Gb} / \mathrm{s} 32 \mathrm{QAM}-\mathrm{OFDM}$ downlink signals with different numbers of sub-carriers are successfully transmitted over 42 km SMF-28. Peak-to average power ratio (PAPR) characteristic, computational complexity and bit error rate (BER) performance are analyzed. The results show that the sub-carriers numbers of 32QAM-OFDM downlink signals should be carefully selected according to the actual requirements, if spectral efficiency, PAPR characteristic, computational complexity and receiver sensitivity are considered.
\end{abstract}

Keywords: PON, 32QAM-OFDM, DMT, PAPR, BER

\section{Introduction}

In recent years, orthogonal frequency-division multiplexing (OFDM) has been widely adopted in many optical access areas, such as OFDM modulated WDM-PONs [1-3] and OFDM-RoF systems [4-9], due to its high spectral efficiency, tolerance to dispersion and flexibility to dynamically bandwidth $[1,10,11]$. At present, few researchers focus on the reception of different $m$-quadrature amplitude modulation (QAM) $(m=4,16,32$, and 64) OFDM downstream signals using self-mixing reception in optical access networks. For simplifying the optical access system configuration and reducing cost budget, we have designed and experimentally demonstrated two kinds of full-duplex $60 \mathrm{GHz}$ radio over fiber systems with 16QAM-OFDM downlink signals generated by discrete multitone (DMT) modulation and demodulation and received by self-mixing reception $[10,11]$. But, few articles report on 32QAM or higher order QAM mapped OFDM optical signals with

\footnotetext{
* Correspondence: syufeng@163.com

College of Electronic and Information Engineering, Chongqing Three Gorges University, Chongqing 404100, China
}

\section{Springer Open}

different numbers of sub-carriers applications in PON systems using DMT modulation and electrical self-mixing reception technique. In addition, although high spectral efficiency transmission and high sensitivity reception of access signals are the focus of attention, the computational complexity in the process of using digital signal processing (DSP) should also be considered. In this paper, we experimentally propose and demonstrate a novel self-mixing detection PON scheme using 5Gb/s 32QAM-OFDM downstream signals through DMT modulation and demodulation. Moreover, peak-to average power ratio (PAPR) characteristic, computational complexity and bit error rate (BER) performance are also analyzed, while different numbers of sub-carriers of 32QAM-OFDM downlink signals are selected.

\section{Modulation and demodulation methods}

As we know, one common method is that while passband OFDM system is used, the digital bit stream is converted first into an equivalent baseband signal, and then to a RF signal through subcarrier modulation. If

(c) The Author(s). 2020 Open Access This article is licensed under a Creative Commons Attribution 4.0 International License, which permits use, sharing, adaptation, distribution and reproduction in any medium or format, as long as you give appropriate credit to the original author(s) and the source, provide a link to the Creative Commons licence, and indicate if changes were made. The images or other third party material in this article are included in the article's Creative Commons licence, unless indicated otherwise in a credit line to the material. If material is not included in the article's Creative Commons licence and your intended use is not permitted by statutory regulation or exceeds the permitted use, you will need to obtain permission directly from the copyright holder. To view a copy of this licence, visit http://creativecommons.org/licenses/by/4.0/. 
DMT is utilized, the bandwidth of the generated electrical spectrum will be enlarged to twice range of the original signal, which is equal to the minimum value of the enlarged bandwidth using subcarrier modulation, where the output of the IFFT modulation is real instead of complex-valued [11]. The schematic diagrams of DMT modulation and demodulation of 32QAM-OFDM downlink signals in the electric field are shown in Fig. 1 as insets (a) and (b), respectively. The DMT is one special subclass of OFDM, using it the output signal after the inverse fast Fourier transform (IFFT) is real valued OFDM signal. The reason why DMT modulation is adopted is that, in traditional OFDM communication system, the time domain data vector is in the form of bipolar complex number, but optical fiber access systems with intensity modulation can only transmit positive real value signals. The DMT modulation and demodulation of 32QAM-OFDM signals is similar to the process in Ref. [12]. When this effective method is introduced in the optical access system, in-phase and quadrature (IQ) will be not required [1]. The system complexity and cost budget could be reduced, since high-frequency microwave source at the optical line terminal (OLT), local oscillator at the optical network unit (ONU) and analog RF components required for IQ modulation are omitted from the transceivers. Moreover, as the number of sub-carriers increases, if each sub-carrier signal is regarded as a remainder signal with random phase, the computational complexity of the DSP will be increased in the process of all sub-carriers superposing to form a DMT signal. And the envelope of the formed DMT signal will fluctuate, which will inevitably lead to a higher peak value, resulting in a higher PAPR value of the muticarrier signal. Therefore, the computational complexity and PAPR negative effects need to be discussed in the subsequent analysis.

\section{Experimental setup and results}

Figure 2 shows the experimental configuration. The linewidth of both two external cavity lasers (ECLs) is 100 $\mathrm{kHz}$. The reason for using the ECL is that it can overcome the disadvantages of the traditional semiconductor laser, such as poor mode stability, large divergence angle and linewidth, and has the characteristics of high stability, small volume and high output power. Two 3paddle fiber polarization controllers (PCs) are connected to the back of the two ECLs through single mode optical fibers, and each PC is adjusted manually to ensure the highest output power of the two continuous light waves. The frequency tone spacing of the two generated free-running continuous wave lightwaves is $60 \mathrm{GHz}$. The reason why $60 \mathrm{GHz}$ is selected is that it can be upgraded to be applied in millimeter wave ROF access systems in the future. A 32QAM-OFDM signal is generated offline and uploaded into one arbitrary wavelength generator (Tektronix AWG 710). In the experiment, DMT modulation and demodulation are used and the number of sub-carriers is dynamically optional (for example, 16, 32, 64, 128, 256, etc. are selected). The length of the cyclic prefix is $1 / 16$ of the symbol time, and a training sequence is inserted every 100 symbols for channel estimation and time synchronization. One $\mathrm{CW}$ is modulated by one intensity modulator $\left(\mathrm{LiNbO}_{3}\right.$ Mach-Zehnder modulator, MZM) driven with the $5 \mathrm{~Gb} / \mathrm{s}$ 32QAM-OFDM signal amplified by one electrical amplifier (EA). The used MZM modulator $(\mathrm{V} \pi=3.6 \mathrm{~V})$ is biased in the quadrature point and driven by by the $5 \mathrm{~Gb} / \mathrm{s}$ signal with a $1 / 2$ half-wave voltage of $1.8 \mathrm{~V}$ for linear modulation. After electro-optic modulation, this 32QAM-OFDM signal is combined by one $3 \mathrm{~dB}$ optical coupler (OC) with the other $\mathrm{CW}$ without signal

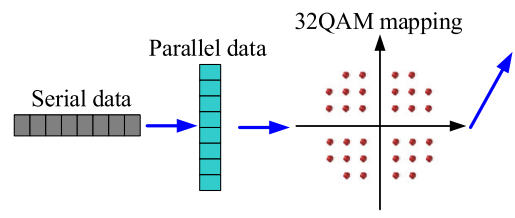

(a) DMT modulation

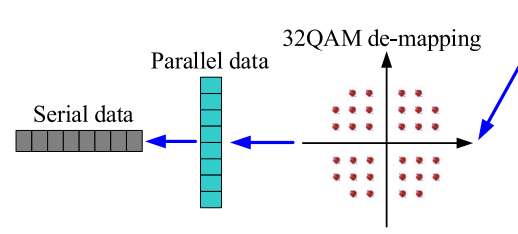

(b) DMT demodulation

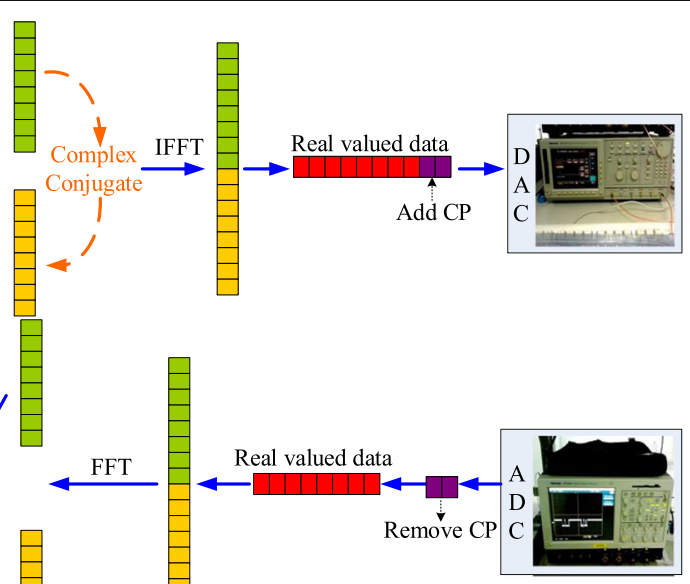

Fig. 1 Block diagrams of the DMT modulation (a) and demodulation (b) of 32QAM-OFDM signals. DMT: discrete multitone; IFFT: inverse fast fourier transform; FFT: fast fourier transform; DAC: Digital to analog converter; ADC: Analog to digital converter 


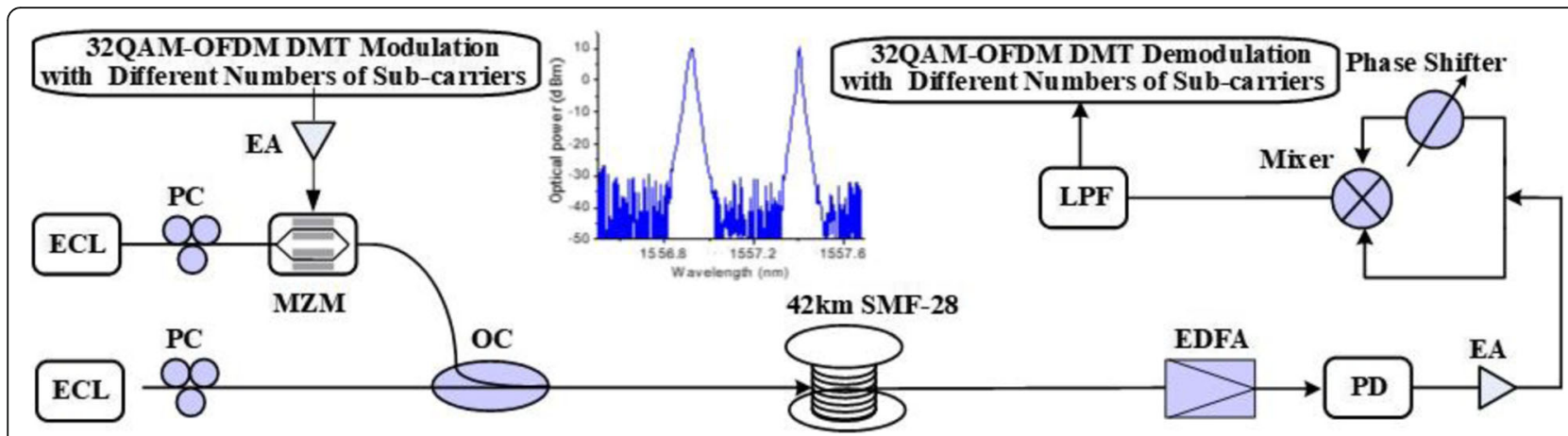

Fig. 2 Experimental setup. ECL: external Cavity Laser; PC: polarization controller; EA:electric amplifier; MZM: Mach-Zehnder modulator; OC: optical coupler; SMF: single mode fiber; EDFA: erbium-doped optical fiber amplifier; PD: photodetector; LPF: low pass filter

modulation. The measured optical spectrum diagram of the downlink signal before transmission is shown in the insert of Fig. 2. In the generated spectrum, one sideband is slightly broadened, which carries the modulated downstream optical signal. The downlink consists of 42 $\mathrm{km}$ single mode fiber (SMF-28) with an erbium-doped fiber amplifier after transmission (EDFA). Subsequently, one PIN PD with a $3 \mathrm{~dB}$ bandwidth of $70 \mathrm{GHz}$ and a DC responsivity of $0.6 \mathrm{~A} / \mathrm{W}$ is used to detect the signal after transmission. The two optical sidebands beat together in the PIN PD and generate a $60 \mathrm{GHz} \mathrm{mm}$-wave electrical signal. The converted electrical signal is amplified by one electrical amplifier with the bandwidth of $10 \mathrm{GHz}$ at the center frequency of $60 \mathrm{GHz}$. After the electrical amplifier, the signal is directly mixed with itself. To match the RF phase information, one adjustable phase shifter was used for self-mixing detection. The generated baseband signal is filtered out by using a low pass filter (LPF). By a digital storage oscilloscope (Tektronix TDS6604), the downstream 32QAM-OFDM signal is obtained. The electrical spectrum diagrams for the back to back (BTB) case and transmission over $42 \mathrm{~km}$ SMF-28 are shown in Fig. 3 (a) and (b), respectively. It is clear to see, the electrical spectrum value of $5 \mathrm{~Gb} / \mathrm{s} 32 \mathrm{QAM}-\mathrm{OFDM}$ signal is $2 \mathrm{GHz}$, which is exactly equal to twice of the electrical spectrum value of the 32QAM-OFDM at the same bit rate using common baseband modulation. The electrical spectrum is extended using DMT method, and the result is the spectral efficiency is sacrificed. However, the DMT modulation and demodulation can eliminate the need for highfrequency microwave source at the OLT and local oscillator at the ONU, which will reduce cost budget, and achieve easy installation and maintenance. Moreover, the results also show the self-mixing detected 32QAMOFDM signal is effective in this experiment.

One of the main drawbacks of the OFDM signal is its high PAPR $[11,13]$. Using DMT modulation and demodulation with number of $N(N=16,32,64,128,256)$ sub-carriers, the measured complementary cumulative distribution function (CCDF) curves of the PAPR of 32QAM-OFDM are shown in Fig. 4. With increasing the number $(N)$ of sub-carriers, there was a corresponding increasing in CCDF value under a certain PAPR threshold. It can be seen that 32QAM-OFDM signals with

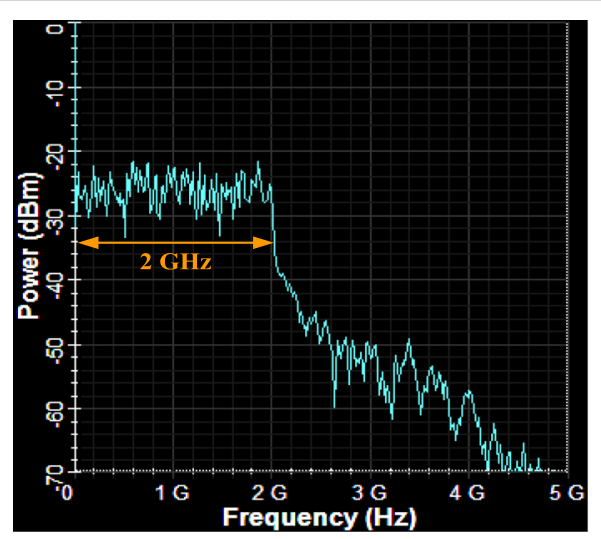

(a) Back to back case

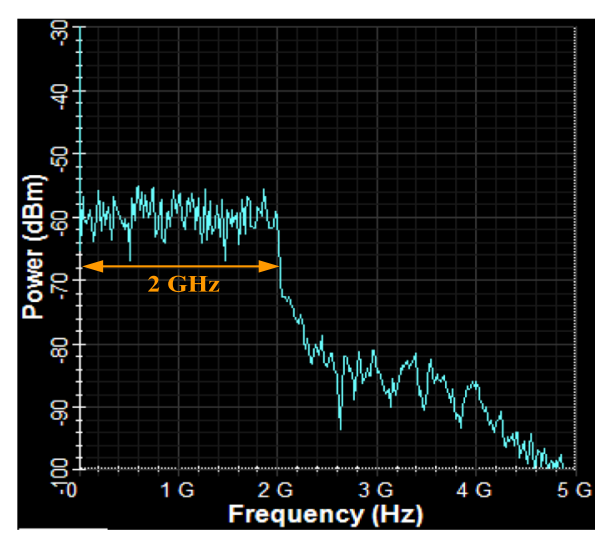

(b) Transmission over $42 \mathrm{~km}$ SMF-2

Fig. 3 Detected electrical spectrum diagrams for the back to back case (a) and transmission over 42 km SMF-28 (b) 


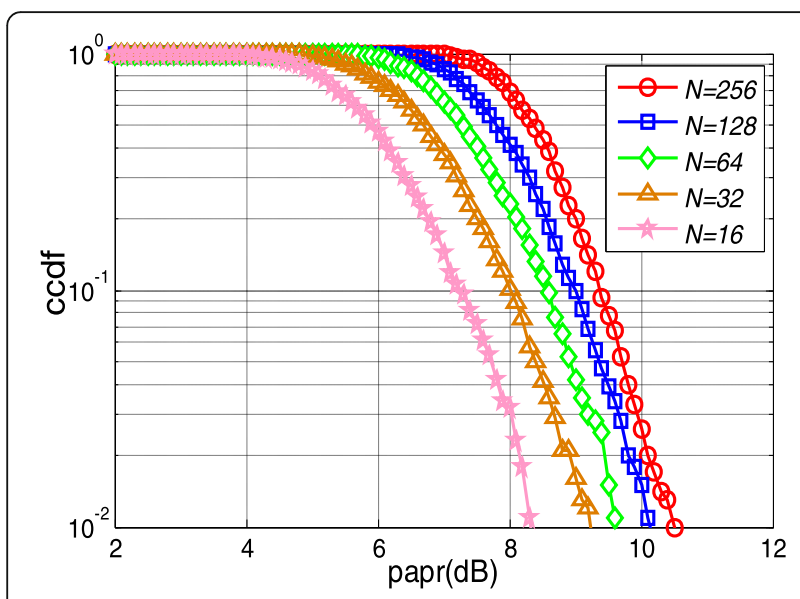

Fig. 4 CCDF curves with different number of $N(N=16,32,64,128$, 256) sub-carriers

small number of sub-carriers have lower PAPR probability than with great number of sub-carriers. Especially for $N=16$, the significant reduction in PAPR is observed. The generated 32QAM-OFDM signal with 16 subcarriers in reducing the PAPR is best using DMT modulation and self-mixing reception. But, in practice, the number of the sub-carriers can not be too few, because the OFDM signal with more sub-carriers has higher spectral efficiency. Another problem can not be ignored is the computational complexity in the DSP of the proposed scheme with different number of sub-carriers.

Figure 5 shows the amount of complex operations in the case of $N=16,32,64,128,256$. It can be seen that the complex operations, including complex multiplications and additions are limited by the numbers of sub-carriers. To reduce the complex operations and PAPR simultaneously, we should choose as few as possible number of $N$ sub-carriers. However, the number of the sub-carriers in the total transmission sequence can not be too few, since the generated

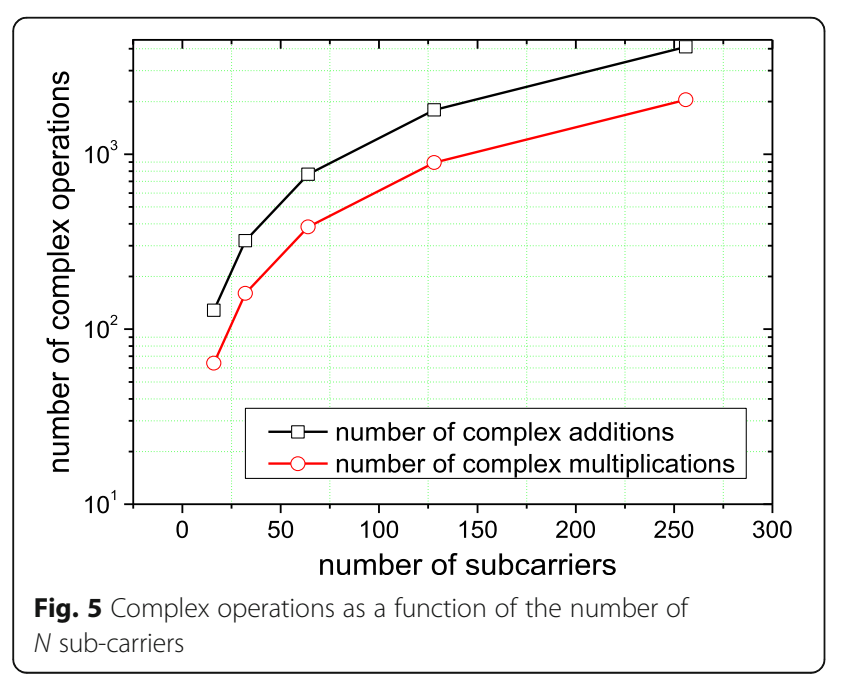

signals with more sub-carriers has higher spectral efficiency, tolerance to dispersion and flexibility to dynamically bandwidth. Moreover, according to the research of existing literature, few researchers chose OFDM signal with lower number of sub-carriers for transmission. If we consider the influence of computational complexity, PAPR and spectral efficiency at the same time, an appropriate number of subcarriers must be chosen.

Figure 6 shows the measured BER curves of $5 \mathrm{~Gb} / \mathrm{s}$ 32QAM-OFDM downlink signals (with 64, 128 and 256 sub-carriers). For the BTB case, regardless of the number of sub-carriers selected for application, the BER results are similar. After transmission over $42 \mathrm{~km}$ SMF-28, the receiver sensitivity (at a BER of $10^{-4}$ ) of the downstream signal with 64 sub-carriers is the best. Compared with the condition with 128 and 256 sub-carriers, the values of the power penalty at $\mathrm{BER}=10^{-4}$ will be reduced, which are almost $0.15 \mathrm{~dB}$ and $0.3 \mathrm{~dB}$, respectively. The results of the above discussion seem to show that the downlink signal with 64 sub-carriers is more suitable for the actual applications, since the receiver sensitivity can be effectively enhanced than with 128 and 256 subcarriers. In combination with the previous discussion, we can see that the PAPR influence and the computational complexity is lower at this case. But, if we expect getting higher spectral efficiency, tolerance to dispersion and flexibility to dynamically bandwidth for 32QAMOFDM signals application, we may choose using more sub-carriers. That is to say, we must make a trade-off selection according to the actual requirements of downlink access signals. Maybe the 32QAM-OFDM signal with 128 sub-carriers is a more suitable access signal, because its receiving sensitivity and spectral efficiency are relatively high, the PAPR value is not very large, and the computational complexity is not prominent.

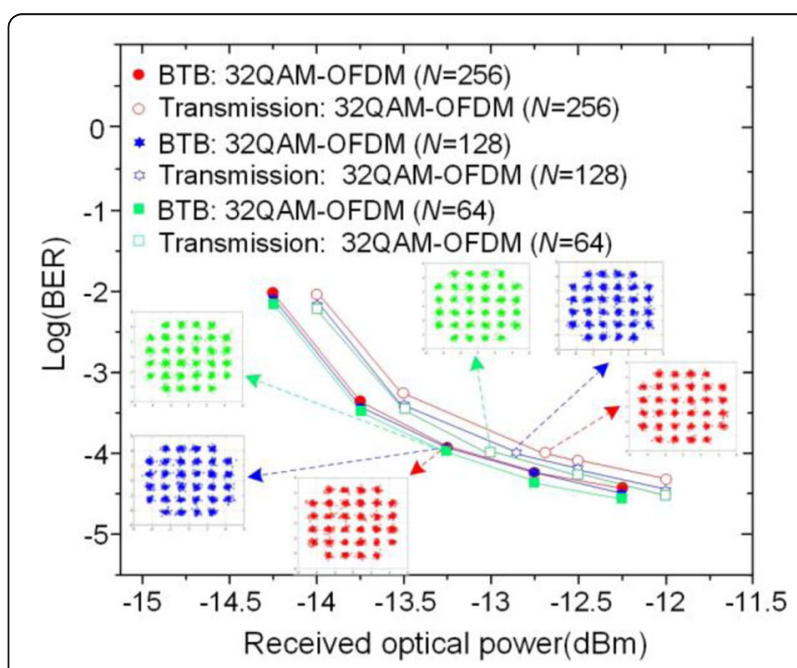

Fig. 6 BER curves of downlink signals, which are all operated at 5Gb/s (with 64, 128 and 256 sub-carriers) 


\section{Conclusion}

In this paper, we have designed and experimentally demonstrated an optical 32QAM-OFDM-PON system with different numbers of sub-carriers. The introduced DMT modulation and demodulation, and the adopted selfmixing detection can effectively reduce system configuration and cost budget, since it eliminates the need for high-frequency microwave source at the OLT and local oscillator at the ONU. Moreover, using this scheme results in good dynamic sub-carriers bandwidth allocation, because different numbers of sub-carriers can be selected according to the actual application. PAPR characteristic, computation complexity, and BER performance of 32QAM-OFDM downlink signals with different numbers of sub-carriers are analyzed. This scheme is potentially valued in future PON networks applications, and can also be upgraded to support radio over fiber PON (RPON) applications while using one PIN PD with a 3 $\mathrm{dB}$ bandwidth of $70 \mathrm{GHz}$ cascaded by a pair of a pair of millimeter wave antennas.

\section{Abbreviations}

QAM: Quadrature amplitude modulation; OFDM: Orthogonal frequency division multiplexing; PON: Passive optical network; DMT: Discrete multitone; PAPR: Peak-to average power ratio; BER: Bit error rate; WDM-

PON: Wavalength division multiplexing-passive optical network; DSP: Digital signal processing; IFFT: Inverse fast Fourier transform; IQ: In-phase and quadrature; ONU: Optical network unit; ECL: External cavity laser; ROF: Radioover-fiber; MZM: Mach-Zehnder modulator; EA: Electrical amplifier; OC: Optical coupler; CW: Continuous-wave; SMF: Single mode fiber; EDFA: Erbium-doped optical fiber amplifier; PIN PD: Positive-intrinsic-negative photodiode; LPF: Low pass filter; BTB: Back to back; OLT: Optical line terminal; CCDF: Complementary cumulative distribution function

\section{Acknowledgments}

This work is partially supported by the National Natural Science Foundation of China (61107064); Science and Technology Research Program of Chongqing Municipal Education Commission (KIZD-M201901201); Chongqing Science and Technology Commission Foundation (cstc2018jcyjAX0038, cstc2016jcyjA0246, cstc2014jcyjA40046); Chongaing University Innovation Team Founding (KTD201320); Science and Technology Research Program of Chongqing Education Commission of China (K11401005); Postgraduate Research Innovation Project of Chongqing Three Gorges College (020752539); Chongqing Three Gorges College Excellent Achievement Transformation Project (18CGZH03); Youth Project of Science and Technology Research Program of Chongqing Education Commission of China (KUQN201801227).

\section{Authors' contributions}

Yufeng Shao conceived and designed the study. Yufeng Shao and Ying Long performed the system configuration, and wrote the manuscript. Yufeng Shao reviewed and edited the paper. All authors read and approved the manuscript.

\section{Funding}

National Natural Science Foundation of China (61107064); Science and Technology Research Program of Chongqing Municipal Education Commission (KJZD-M201901201); Chongqing Science and Technology Commission Foundation (cstc2018jcyjAX0038, cstc2016jcyjA0246, cstc2014jcyjA40046); Chongqing University Innovation Team Founding (KJTD201320); Science and Technology Research Program of Chongqing Education Commission of China (KJ1401005); Postgraduate Research Innovation Project of Chongqing Three Gorges College (020752539); Chongqing Three Gorges College Excellent Achievement Transformation Project (18CGZH03); Youth Project of Science and Technology Research Program of Chongqing Education Commission of China (KJQN201801227).

\section{Availability of data and materials}

All data and materials are fully available without restriction.

\section{Competing interests}

The authors declare that they have no competing financial interests.

Received: 29 February 2020 Accepted: 23 April 2020

Published online: 06 May 2020

\section{References}

1. Shao, Y., Wang, Y., Chi, N.: 60-GHz RoF system with low PAPR 16QAM-OFDM downlink using PTS segmentation. IEEE Photon. Technol. Lett. 25, 255-258 (2013)

2. Chow, C.W., Yeh, C.H., Xu, L., Tsang, H.: Rayleigh backscattering mitigation using wavelength splitting for heterogeneous optical wired and wireless access. IEEE Photon. Technol. Lett. 22, 1294-1295 (2010)

3. Zhu, Y., Wu, Y., Xu, H., Browning, C., et al.: Experimental Demonstration of a WDM-RoF Based Mobile Fronthaul with f-OFDM Signals by Using Directly Modulated 3s-DBR Laser. J. Lightwave Technol. 37, 3875-3881 (2019)

4. Qian, D., Cvijetic, N., Hu, J., Wang, T.: 108 Gb/s OFDMA-PON with polarization multiplexing and direct detection. IEEE J. Lightw. Technol. 28, 484-493 (2010)

5. Lin, C.-T., Shih, P.-T., Chen, J., Xue, W., Peng, P., Chi, S.: Optical millimeterwave signal generation using frequency quadrupling technique and no optical filter. IEEE Photon. Technol. Lett. 20(12), 1027-1029 (2008)

6. Shao, Y., Chi, N., Fan, J., Wang, Y., Fang, W.: Novel centralized-light-source WDM-RoF system with OFDM-CPM downstream and OOK upstream. Optics Comm. 285, 3437-3440 (2012)

7. Jiang, W., Lin, C., Shih, P., Chen, J., Peng, P., Chi, S.: A full duplex radio-overfiber link with multi-level OFDM signal via a single electrode MZM and wavelength reuse with a RSOA. Opt. Express. 18, 2710-2718 (2010)

8. Huang, H.T., Lin, C.T., Chiang, S.C., et al.: Volterra nonlinearity compensator for I/Q imbalanced Mm-Wave OFDM RoF systems. In: 2015 International Topical Meeting on Microwave Photonics (MWP). (2015)

9. Ye, J., Yan, L., et al.: Phase-shift assisted OFDM-RoF transmission employing optical heterodyning. In: 2017 International Topical Meeting on Microwave Photonics (MWP). (2017)

10. Shao, Y., Chi, N., Fan, J., Fang, W.: Generation of 16-QAM-OFDM signals using selected mapping method and its application in optical millimeter-wave access system. IEEE Photon. Technol. Lett. 24, 1301-1303 (2012)

11. Shao, Y.: PAPR reduction and receiver sensitivity improvement in 16QAMOFDM RoF system using DMT modulation and BTN-PS technique. Optical and laser technology. Opt. Laser Technol. 77, 59-63 (2016)

12. Lee, S.C.J., Breyer, F., Randel, S., Henrie, P., van den Boom, A., Koonen, A.M.J.: High-speed transmission over multimode fiber using discrete multitone modulation. J. Opt. Networking. 7, 183-196 (2008)

13. Chen, X., Li, A., Gao, G., Shieh, W.: Experimental demonstration of improved fiber nonlinearity tolerance for unique-word DFT-spread OFDM systems. Opt. Express. 19, 26198-26207 (2011)

\section{Publisher's Note}

Springer Nature remains neutral with regard to jurisdictional claims in published maps and institutional affiliations.

\section{Submit your manuscript to a SpringerOpen ${ }^{\circ}$ journal and benefit from:}

- Convenient online submission

- Rigorous peer review

- Open access: articles freely available online

High visibility within the field

- Retaining the copyright to your article

Submit your next manuscript at $>$ springeropen.com 